This item was submitted to Loughborough's Research Repository by the author.

Items in Figshare are protected by copyright, with all rights reserved, unless otherwise indicated.

\title{
Transmission line modelling of cylindrical cavity loaded with a slotted
} dielectric rod

PLEASE CITE THE PUBLISHED VERSION

https://doi.org/10.1109/RFM.2015.7587706

PUBLISHER

(C) IEEE

VERSION

AM (Accepted Manuscript)

LICENCE

CC BY-NC-ND 4.0

\section{REPOSITORY RECORD}

Agunlejika, Oluwafunmilayo, James A. Flint, and R.D. Seager. 2019. "Transmission Line Modelling of Cylindrical Cavity Loaded with a Slotted Dielectric Rod”. figshare. https://hdl.handle.net/2134/33396. 


\title{
Transmission Line Modelling of Cylindrical Cavity Loaded with a Slotted Dielectric Rod
}

\author{
O. Agunlejika*, J. A. Flint and R. D. Seager \\ School of Electronic, Electrical and Systems Engineering, Loughborough University, LE11 3TU, United Kingdom \\ *O.Agunlejika@lboro.ac.uk,J.A.Flint@lboro.ac.uk,R.D.Seager@lboro.ac.uk
}

\begin{abstract}
This paper examines the effect of loading a microwave cylindrical cavity with radially slotted dielectric rod. Although, methods for the computation of the resonant frequency of dielectric loaded cavity have been presented in the literatures, the effect of placing radial slots on axisymmetric dielectric load in relation to the cavity resonance has not been studied. The study was carried out using a cylindrical TLM solver developed in MATLAB. A parametric check on the effect of varying the slot depth and width shows that the slot width has greater effect on the cavity resonance than the slot depth. It was also discovered that multiple narrow slots on the load affects the resonance frequency of the cavity more than a single wide slot. The effect of periodicity of the slots on the resonance frequency was also examined.
\end{abstract}

Keywords - cylindrical cavity; dielectric loaded cavity; resonant frequency; transmission line modelling

\section{INTRODUCTION}

Dielectric loaded cavities are special type of resonator and have found applications in microwave filters for satellite and mobile communication as a result of their small size, low loss and temperature stability [1], [2]. These applications have attracted further research and there are a significant number of publications reporting the numerical calculation of resonant frequencies of canonical metallic cavities loaded with dielectric resonators [3]-[9].

The perturbation method [10], [11], where a dielectric/metallic rod is inserted into the cavity, is the most common practice to tune the resonant frequency of the cavity. With this method, the resonant frequency of the cavity can be controlled by the material properties of the inserted rod or by adjusting the amount of penetration into the cavity [12]. The method proposed in this paper uses a slotted dielectric rod, in the place of plain dielectric rod, to tune the resonant frequency of a cavity. A parametric check on the effect of varying the depth and width of the slot on the resonant frequency of the cavity was carried out. The effect of periodically arranging the slot on the load was also investigated.

\section{METHOD}

The cylindrical Transmission Line Matrix (TLM) method was used for this study because the method provides a suitable procedure for the simulation of this type [13]. TLM is known to be a versatile numerical tool in solving electromagnetic problems because of its stability, ease of application and capability for wideband applications and its ability to take into account the material properties [14]-[16]. A solver was developed, based on cylindrical TLM using MATLAB, for the cavity simulations.

In order to verify the accuracy of the developed solver, an air-filled cylindrical cavity (relative permittivity, $\varepsilon_{r}=1$ and relative permeability, $\mu_{r}=1$ ) with known analytical solution was modelled using the developed solver. The radius, $r_{c}$ of the cylindrical cavity is $40 \mathrm{~mm}$ and the height, $h$ is $75 \mathrm{~mm}$.

The analytical resonant frequency $\left(f_{n m l}\right)$ was calculated as:

$$
f_{n m l}=\frac{1}{2 \pi \sqrt{\mu \varepsilon}} \sqrt{\left(\frac{P_{n m}}{r_{c}}\right)^{2}+\left(\frac{l \pi}{h}\right)^{2}}
$$

where $\mu$ and $\varepsilon$ are absolute permittivity and permeability respectively and $P_{n m}$ is given in TABLE I:

TABLE I. Comparison of the analytical results with the simulated results for the cavity loaded with plain dielectric rod.

\begin{tabular}{|c|c|c|c|}
\hline$n$ & $P_{n 1}$ & $P_{n 2}$ & $P_{n 3}$ \\
\hline 0 & 2.405 & 5.520 & 8.654 \\
\hline 1 & 3.832 & 7.016 & 10.174 \\
\hline 2 & 5.135 & 8.417 & 11.629 \\
\hline
\end{tabular}

The cavity was excited such that only the Transverse Magnetic (TM) modes were generated. The analytical resonant frequency for the dominant mode (TM 010) of the air-filled cylindrical cavity is $2.8708 \mathrm{GHz}$. The simulated frequency $2.8740 \mathrm{GHz}$ compared with the analytical result is accurate to less than $0.1 \%$ error. The simulated result is as shown in Fig. 1. Having confirmed the result of the solver for the unloaded cavity is satisfactory, the first mode of the cavity is set as the point of reference for all other results.

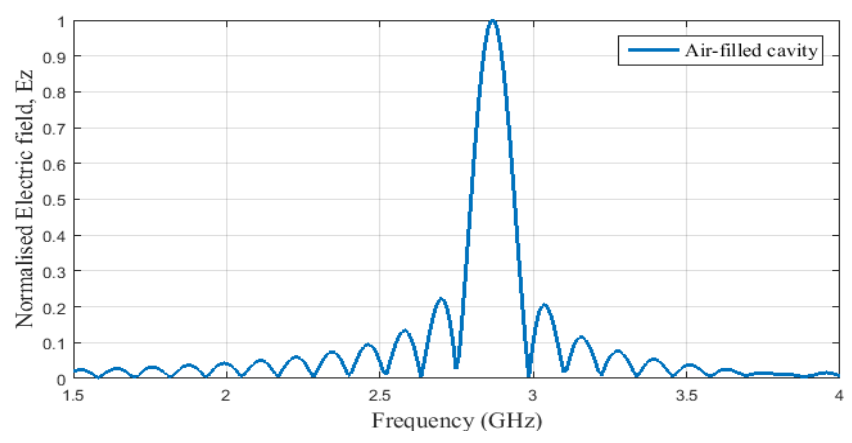

Fig. 1. Simulated resonant frequency for an air-filled cylindrical cavity 
The effect of a plain dielectric rod on the resonant frequency of the cavity was first investigated as a benchmark for its slotted counterpart. The dielectric loaded cylindrical cavity problem presented by Chan et al. [17] was simulated using the developed cylindrical TLM solver. The loading dielectric rods considered was coaxially positioned at the center of the cylindrical cavity as shown in Fig. 2a. The dielectric load was $20 \mathrm{~mm}$ in diameter with permittivity, $\varepsilon_{r}=$ 25.

The distribution of the permittivity in the coaxially dielectric-loaded cavity is anisotropic in nature unlike the airfilled cavity with evenly distributed permittivity at every point in space. In the dielectric-loaded case, there are two materials of different permittivity values inside the cavity - air $\left(\varepsilon_{r}=1\right)$ and the dielectric material $\left(\varepsilon_{r}=25\right)$. In order to minimise errors due to mesh dispersion, the permittivity difference should be taken into account when dealing with the space discretisation of TLM [18]. Generally, the choice of discrete length $(\Delta l)$ in TLM model depends on the shortest wavelength of interest. It is recommended that $\Delta l$ should be less than $\lambda / 10$ in order to avoid dispersion error [19]. Therefore, to implement the dielectric load correctly, $\lambda / 10$ dispersion constraint means that the dielectric material with higher relative permittivity value requires corresponding smaller nodes. Number of nodes in the dielectric layer is calculated as the ratio of the number of nodes in the air to the square root of the permittivity value of the dielectric material.

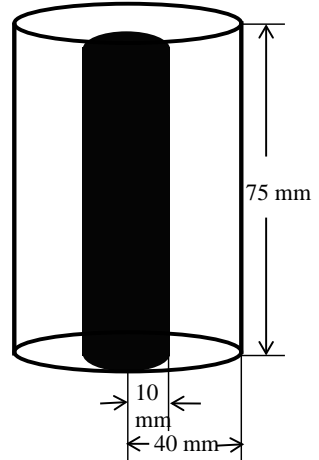

(a) Plain dielectric rod load

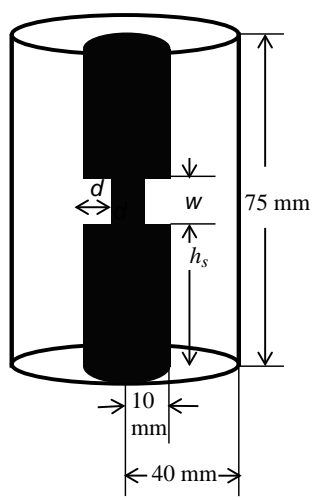

(b) slotted dielectric rod load
Fig. 2. Simulated dielectric loaded cylindrical cavity

The simulated results compared well with the analytical results and the simulated results obtained by Chan et al [17]. The simulated results from the developed solver also compared well with the simulated results obtained by Jukovic et al. [20] for the same problem. The results are as shown in Table 1. When the result of the solver is confirmed satisfactory, the first mode of the dielectric-rod loaded cavity is set as the point of reference for all other results.
TABLE II. Comparison of the analytical results with the simulated results for the cavity loaded with plain dielectric rod.

\begin{tabular}{|l|l|l|l|l|}
\hline Mode & $\begin{array}{l}\text { Analytical } \\
(\mathrm{GHz})\end{array}$ & $\begin{array}{l}\text { Chow } \\
(\mathrm{GHz})\end{array}$ & $\begin{array}{l}\text { Jukovic } \\
(\mathrm{GHz})\end{array}$ & $\begin{array}{l}\text { Simulated } \\
(\mathrm{GHz})\end{array}$ \\
\hline TM010 & 1.0189 & 1.019 & 1.0396 & 1.019 \\
\hline TM020 & 3.5702 & 3.574 & 3.5592 & 3.567 \\
\hline
\end{tabular}

\section{SLOTTED DIELECTRIC-RoD-LOADED CAVITY: SiMULATION AND RESULT DISCUSSIONS}

A radial slot of width, $w$ and depth $d$ was cut into the dielectric rod described in section II at height, $h_{s}$ as shown in Fig. 2b. A parametric study of the effect of varying both the $w$ and $d$ on the resonant frequency was carried out. The size of $w$ was varied while keeping $d$ at $5 \mathrm{~mm}$ and the result is as shown in Fig. 3. The size of $d$ was then varied while keeping $w$ at $5 \mathrm{~mm}$ and the result is as shown in Fig. 4. It is observed that both variations in width and in depth affect the resonance proportionately but the width however has higher effect on the resonant frequency of the cavity than the depth (See Fig. 5). It can be deduced from these results that a slot-dielectric rod with well calculated width and depth can be used to control the resonant frequency of the cavity in a significant way.

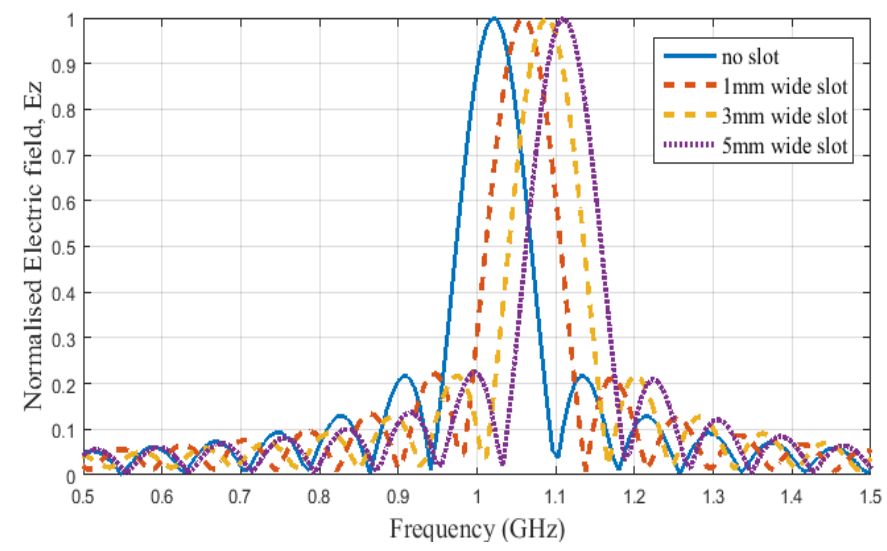

Fig. 3. Effect of slot width variation on the resonant frequency of the cavity with $d=5 \mathrm{~mm}, h_{s}=38 \mathrm{~mm}$.

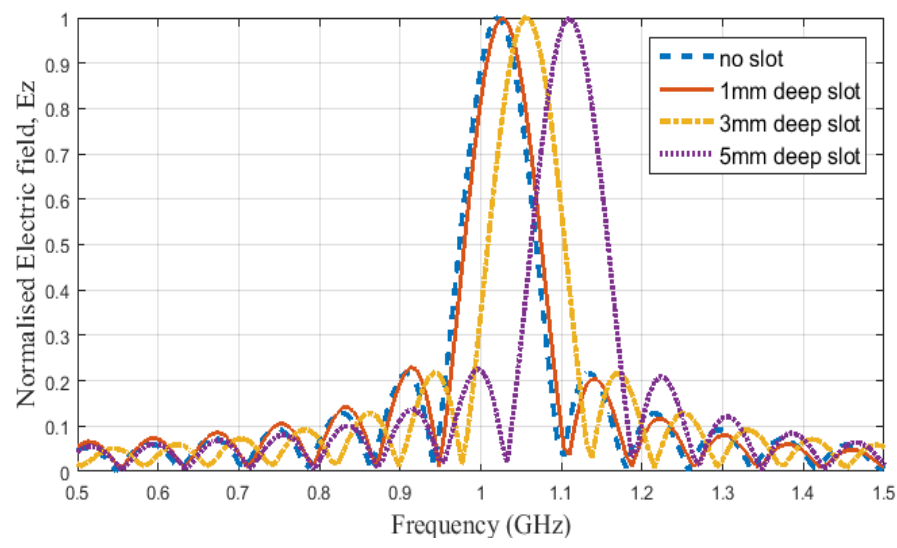

Fig. 4. Effect of varying the slot depth on the resonant frequency of the cavity with $w=5 \mathrm{~mm}, h_{s}=38 \mathrm{~mm}$ 


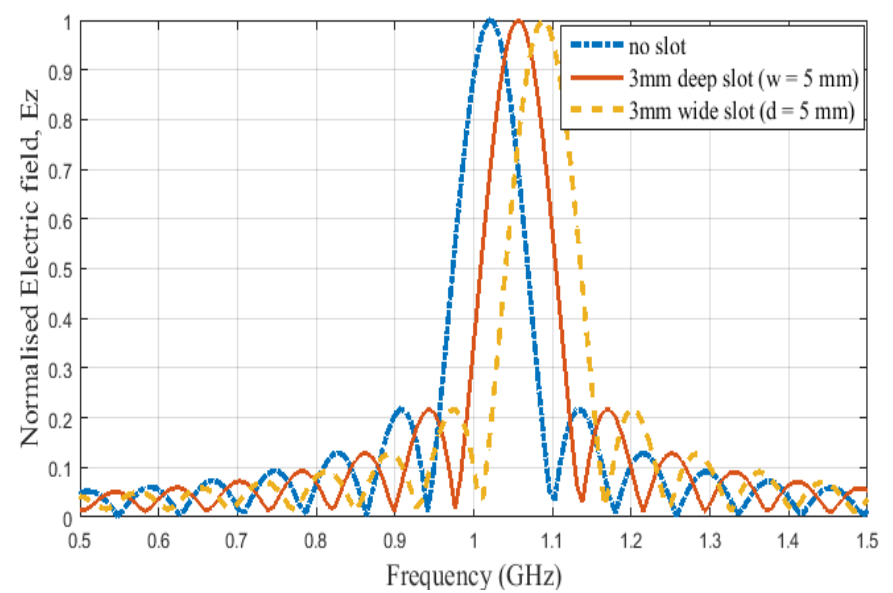

Fig. 5. Comparison of the effect of slot depth and slot width on the resonant frequency of the cavity with $h_{s}=38 \mathrm{~mm}$.

To investigate the effect of multiple slots on the cavity resonance, more slots were added to the dielectric load. The gap between two slots was set to the same value at all times and equal $w$ and $d$ were maintained for all slots. The result is as shown in Fig. 6. It is observed that the higher the number of slots incorporated on the load, the higher the frequency becomes.

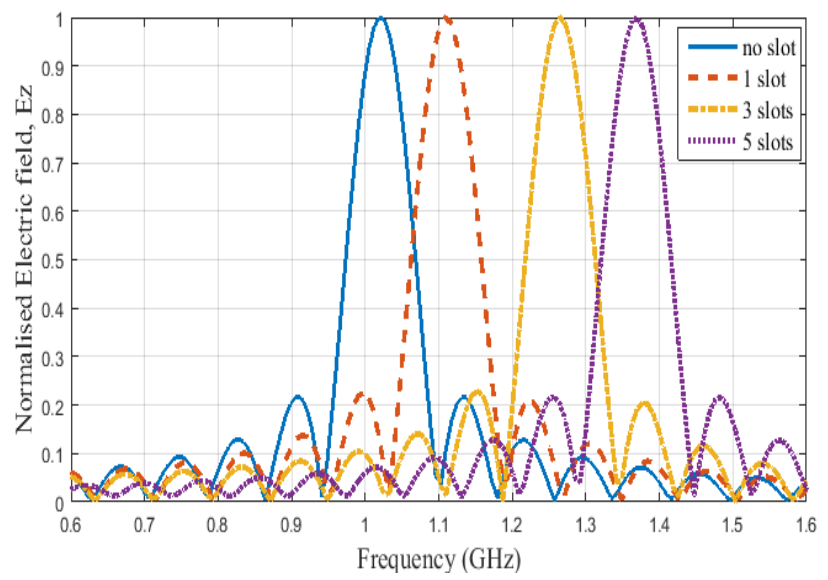

Fig. 6. Effect of multiple slots on the resonant frequency of the cavity $\left(h_{s}=\right.$ $38 \mathrm{~mm}$ for 1 slot, $h_{s}=30,40$ and $50 \mathrm{~mm}$ for the 3 slots and $h_{s}=$ $20,30,40,50$ and $60 \mathrm{~mm}$ for the 5 slots.

Further investigation is required to fully understand the effect of the slot positioning on the resonant frequency of the cavity. There was no visible effect shown in association with the positioning of a single slot at different location on the dielectric load. The positions of slots were varied in order to check the effect of positioning in multiple slots application, while keeping the $w$ and $d$ constant. The results are as shown in Fig. 7. It could be deduced from the results in Fig. 7 that the effect of the slot location on the resonant frequency of the cavity is not as significant as that of the width, the depth and the periodicity of the slots.

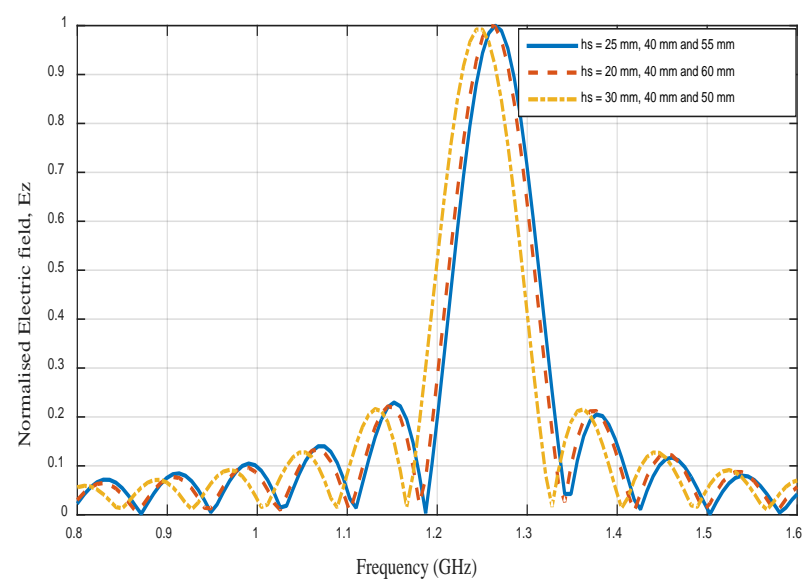

Fig. 7. Effect of slot location on the resonant frequency of the cavity

In order to verify further the effect of the multiple slots, the result of the simulation for three $5 \mathrm{~mm}$ slots was compared with that of a single $15 \mathrm{~mm}$ wide slot while keeping the depth at $5 \mathrm{~mm}$. The result shows that the three narrow slots produced a higher shift in the resonant frequency as depicted in Fig. 8.

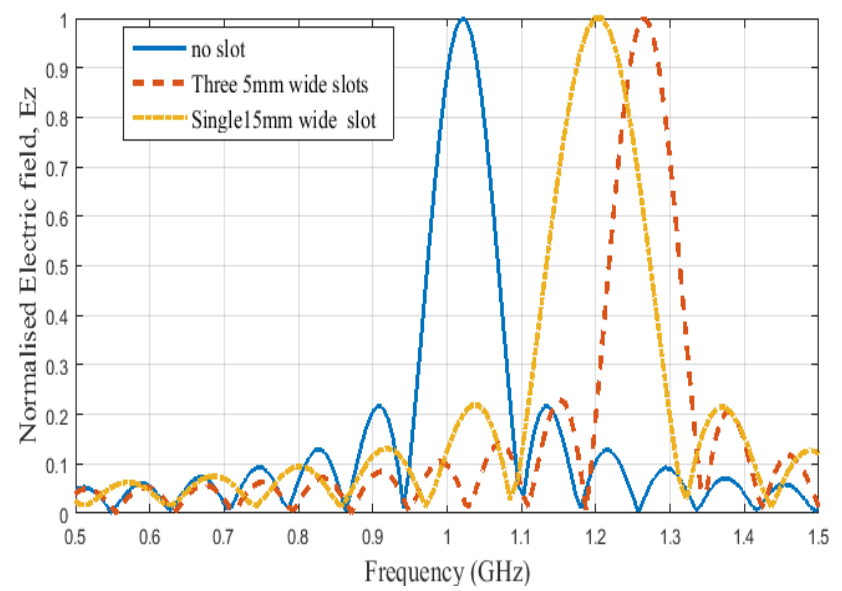

Fig. 8. Comparison of a single slot $\left(w=15 \mathrm{~mm}, h_{s}=38 \mathrm{~mm}\right.$ ) to three narrow slots of combined equivalent width $\left(w=5 \mathrm{~mm}, h_{s}=\right.$ 30,40 and $50 \mathrm{~mm}$ ).

It can be deduced from the result that it is more effective to shift the resonant frequency higher with multiple slots than with a single wide slot. This result also shows that the increase in the frequency is not just as a result of reduction in the total volume of the dielectric at the center of the cavity but also due to the position of the slot on the load.

\section{CONCLUSIONS}

The effects of the dielectric load with slot on the resonant frequency of the cavity have been determined using the TLM method. An electromagnetic solver was developed in MATLAB based on cylindrical TLM algorithm and was applied to the modelling of a cylindrical cavity loaded with a slotted dielectric rod. A parametric study of the effect of slot's width, slot's depth and the periodicity of the slot on the dielectric rod was carried out in order to determine how these variations affect the operating frequency of the cavity. 
The numerical results obtained show that a cavity loaded with a slotted dielectric rod resonates at a higher frequency in comparison with its conventional plain dielectric rod of the same diameter. This frequency can further be increased by increasing the width and depth of the slot or by using multiple slots. Application of multiple slots on the dielectric rod was found to produce higher resonant frequency compared to a single wide slot of equivalent width.

Therefore, slotted dielectric rod with well-calculated depth and width can be used to control or regulate the frequency of cylindrical cavity resonators. Moreover, the method gives room for reusability as a single dielectric material can be used for different purposed by controlling the resonant frequency with the application of slot(s).

\section{ACKNOWLEDGMENT}

This research was partly supported by both the Schlumberger foundation and the Petroleum Technology Development Fund of Nigeria.

\section{REFERENCES}

[1] J. A. Monsoriu, B. Gimeno, E. Silvestre, and M. V. Andres, "Analysis of inhomogeneously dielectric filled cavities coupled to dielectric-loaded waveguides: application to the study of NRD-guide components," IEEE Trans. Microw. Theory Tech., vol. 52, no. 7, 2004.

[2] A. P. Duffy, M. Johnson, D. J. Hill, and T. M. Benson, "Analysis of Microwave Resonators using

Transmission Line Modelling,” IEE Proc - Sci Meas. Technol, vol. 143, no. 6, pp. 362-368, 1996.

[3] H. Tanaka and A. Tsutsumi, "Resonant Frequency and Q-Factor of a Dielectric-Loaded-Cavity Resonator with a Conductive Layer on Its Metal Wall,” Jpn. J. Appl. Phys., vol. 42, no. Part 2, No. 11B, pp. L1400L1403, Nov. 2003.

[4] E. O. Ammann, “Tunable, Dielectric-Loaded Microwave Cavities Capable of High Q and High Filling Factor,” IEEE Trans. Microw. Theory Tech., vol. 11, no. 6, pp. 528-541, 1963.

[5] S. Verdeyme, P. Guillon, S. Vigneron, B. Theron, L. C. Espace-, T. C. Two, and F. E. Method, “A New Dielectric Loaded Cavity for High Power Microwave Filtering,” Optimization, pp. 615-618, 1996.

[6] B. Milovanovic, N. Doncov, and A. Atanaskovic, "TLM modelling of cylindrical metallic cavity loaded by inhomogeneous dielectric sample,” 2000 10th Mediterr. Electrotech. Conf. Inf. Technol. Electrotechnol. Mediterr. Countries. Proceedings. MeleCon 2000 (Cat. No.00CH37099), vol. 1, 2000.
[7] S. N. Doncov, B. . D. Milovanovic, and S. T. Ivkovic, "Modelling of circular cylindrical metallic cavity loaded by a lossy dielectric sample of various geometries using 3-D TLM method,” Microw. Rev., 1998.

[8] P. S. Kooi, M. S. Leong, and S. P. Yeo, “Circular cylindrical cavity loaded with a dielectric sleeve for Gunn-effect oscillator stabilisation application,” IEE Proc. H Microwaves, Antennas Propag., vol. 133, no. 4, p. 259, 1986.

[9] A. J. M. Williams, T. M. Benson, and A. P. Duffy, "Determining the accuracy of TLM in simulating the behaviour of resonant cavities with arbitrary dielectric loading,” Int. J. Electron., vol. 83, no. 5, pp. 645-660, 1997.

[10] S. Maruoka, Y. Nikawa, T. Izumikawa, and S. Maji, "Oversized cylindrical cavity to measure complex permittivity in millimeter waves," 2009 Asia Pacific Microw. Conf., no. 3, pp. 337-340, Dec. 2009.

[11] H. Kawabata, Y. Kobayashi, and S. Kaneko, "Analysis of Cylindrical Cavities to Measure Accurate Relative Permittivity and Permeability of Rod Samples," in Proceedings of Asia-Pacific Microwave Conference 2010, 2010, pp. 1459-1462.

[12] A. Parkash, J. K. Vaid, and A. Mansingh,

"Measurement of Dielectric Parameters at Microwave Frequencies by Cavity-Perturbation Technique,” IEEE Trans Microw. theory Tech., vol. MTT.27, no. 1, pp. 791-795, 1979.

[13] Yi-chi Shih and J. R. Hoefer, "The Accuracy of TLM Analysis of Finned Rectangular Waveguides,” IEEE Trans. Microw. Theory Tech., vol. 28, no. 7, pp. 743746, 1980.

[14] C. Christopoulos, The Transmission-Line Modeling Method (TLM). IEEE/OUP Press, 1995.

[15] A. P. Duffy, J. L. Herring, T. M. Benson, and C. Christopoulos, "A new wire representation for TLM," 1993 Int. Symp. Electromagn. Compat., 1993.

[16] P. B. Johns, “The Art of Modelling,” Electron. Power, vol. 25, no. 8, pp. 565-569, 1979.

[17] T. V. C. T. Chan and H. C. Reader, Understanding Microwave Heating Cavities. Boston, London: Artech House, 2000. 
[18] A. Taflove and S. C. Hagness, Computational Electrodynamics: the Finite Difference Time-Domain Method, 3rd ed. Norwood MA: Artech House, 2005.

[19] C. Christopoulos, The Transmission-Line Modeling (TLM) Method in Electromagnetics. Morgan and Claypool, 2006.

[20] J. Jokovic and T. Dimitrijevic, "TLM cylindrical model of a coaxially loaded cylindrical cavity,” 2011 10th Int. Conf. Telecommun. Mod. Satell. Cable Broadcast. Serv. TELSIKS 2011 - Proc. Pap., vol. 2, pp. 420-423, 2011. 